\title{
The Supramolecular Organization of a Peptide-Based Nanocarrier at High Molecular Detail
}

\author{
Mazda Rad-Malekshahi, ${ }^{\ddagger}$ Koen M. Visscher, ${ }^{\dagger}$ João P. G. L. M. Rodrigues, ${ }^{\dagger}$ Renko de Vries, ${ }^{\S}$ \\ Wim E. Hennink, ${ }^{\ddagger}$ Marc Baldus, ${ }^{\dagger}$ Alexandre M. J. J. Bonvin, ${ }^{*}{ }^{\dagger}$ Enrico Mastrobattista, ${ }^{*}$, \\ and Markus Weingarth ${ }^{* \dagger}$
}

${ }^{\dagger}$ NMR Spectroscopy, Bijvoet Center for Biomolecular Research, Department of Chemistry, Faculty of Science, Utrecht University, Padualaan 8, $3584 \mathrm{CH}$ Utrecht, The Netherlands

${ }^{*}$ Department of Pharmaceutics, Utrecht Institute for Pharmaceutical Sciences, Utrecht University, 3584 CG Utrecht, The Netherlands

${ }^{\S}$ Laboratory of Physical Chemistry and Colloid Science, Wageningen University, Dreijenplein 6, 6703 HB Wageningen, The Netherlands

\section{Supporting Information}

ABSTRACT: Nanovesicles self-assembled from amphiphilic peptides are promising candidates for applications in drug delivery. However, complete high-resolution data on the local and supramolecular organization of such materials has been elusive thus far, which is a substantial obstacle to their rational design. In the absence of precise information, nanovesicles built of amphiphilic "lipid-like" peptides are generally assumed to resemble liposomes that are organized from bilayers of peptides with a tail-to-tail ordering. Using the nanocarrier formed by the

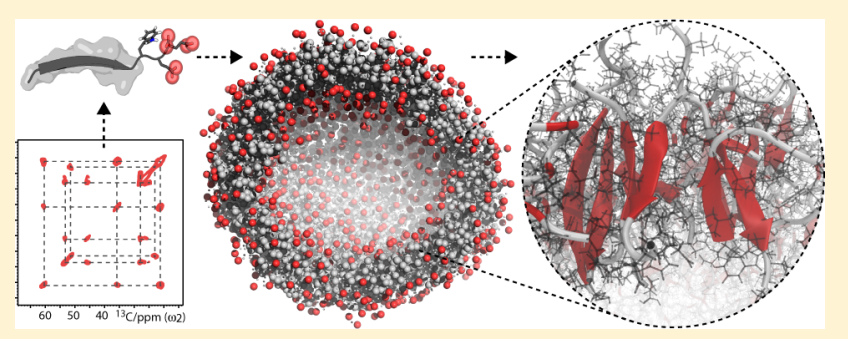
amphiphilic self-assembling peptide 2 (SA2 peptide) as an example, we derive the local and global organization of a multimegaDalton peptide-based nanocarrier at high molecular detail and at close-to physiological conditions. By integrating a multitude of experimental techniques (solid-state NMR, AFM, SLS, DLS, FT-IR, CD) with large- and multiscale MD simulations, we show that SA2 nanocarriers are built of interdigitated antiparallel $\beta$-sheets, which bear little resemblance to phospholipid liposomes. Our atomic level study allows analyzing the vesicle surface structure and dynamics as well as the intermolecular forces between peptides, providing a number of potential leads to improve and tune the biophysical properties of the nanocarrier. The herein presented approach may be of general utility to investigate peptide-based nanomaterials at high-resolution and at physiological conditions.

\section{INTRODUCTION}

Nanovesicles based on self-assembling amphiphilic peptides show great potential for controlled and safe drug delivery. ${ }^{1-8}$ Next to their inherent biodegradability, ${ }^{9-11}$ the great appeal of peptides as building blocks for nanotechnology is their availability by solid-state synthesis and the ease with which their biophysical properties and functions can be tuned by changing the amino acids sequence or by conjugating chemical groups. ${ }^{12}$ Moreover, peptide-based nanoparticles can be equipped with bioactive epitopes that interact with cells or proteins. ${ }^{13}$ Hence, peptide-based drug delivery systems could potentially be designed for many biomedical purposes, which requires control of their structural and functional aspects at a molecular level. However, since peptide-based nanovesicles are not amenable to high-resolution crystallography and too large (>MDa) for solution NMR, atomic-resolution data on the molecular and supramolecular organization of such nanomaterial is sparse and fragmentary, which represents a considerable obstacle to their efficient rational design. The use of highresolution methods is further limited by the requirement of close-to physiological experimental conditions since the vesicle assembly process may be sensitive to the molecular environment. $^{2}$

Here we present an avenue to the high-resolution structural characterization of peptide-based nanovesicles and their assembly pathway based on the example of the nanocarrier formed by the self-assembling peptide 2 (SA2 peptide). ${ }^{14}$ This amphiphilic decapeptide, Ac-AAVVLLLWEE-COOH, spontaneously self-assembles into hollow spheres that bear potential as drug delivery systems. ${ }^{15}$ The design of the SA2 peptide aimed at a conical shape, with a strongly negatively charged Cterminus, followed by a hydrophobic domain, which decreases in size toward the N-terminus. In the absence of sufficient highresolution data, spherical assemblies of amphiphilic peptides are generally thought to adopt liposome-like structures composed of bilayers of parallel peptides with a tail-to-tail organization. ${ }^{1,16,17}$ By integrating an ensemble of experimental methods (solid-state NMR, AFM, SLS, DLS, FT-IR, CD) with large- and multiscale molecular dynamics simulations, we describe the

Received: March 26, 2015

Published: May 28, 2015 

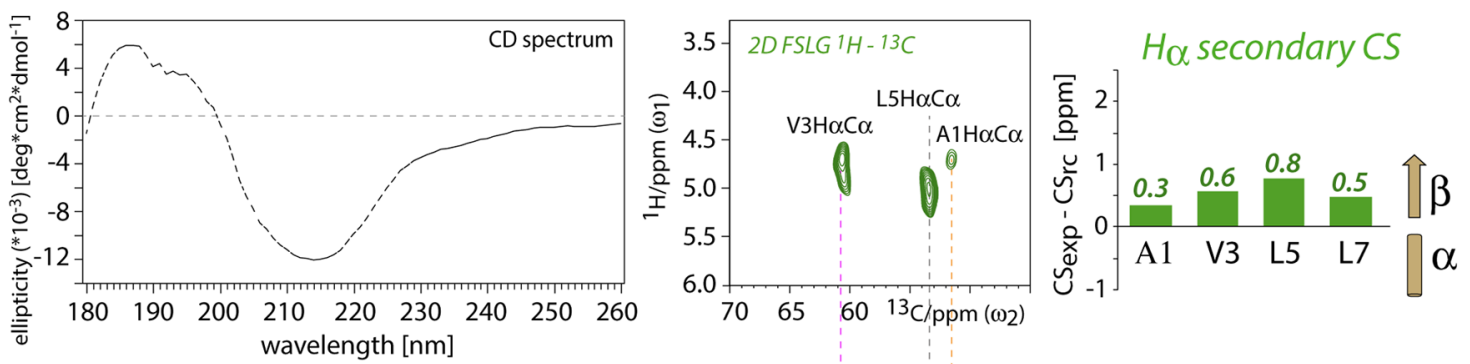

\section{$\left[C_{\alpha}-C_{\beta}\right]$ secondary $C S$}
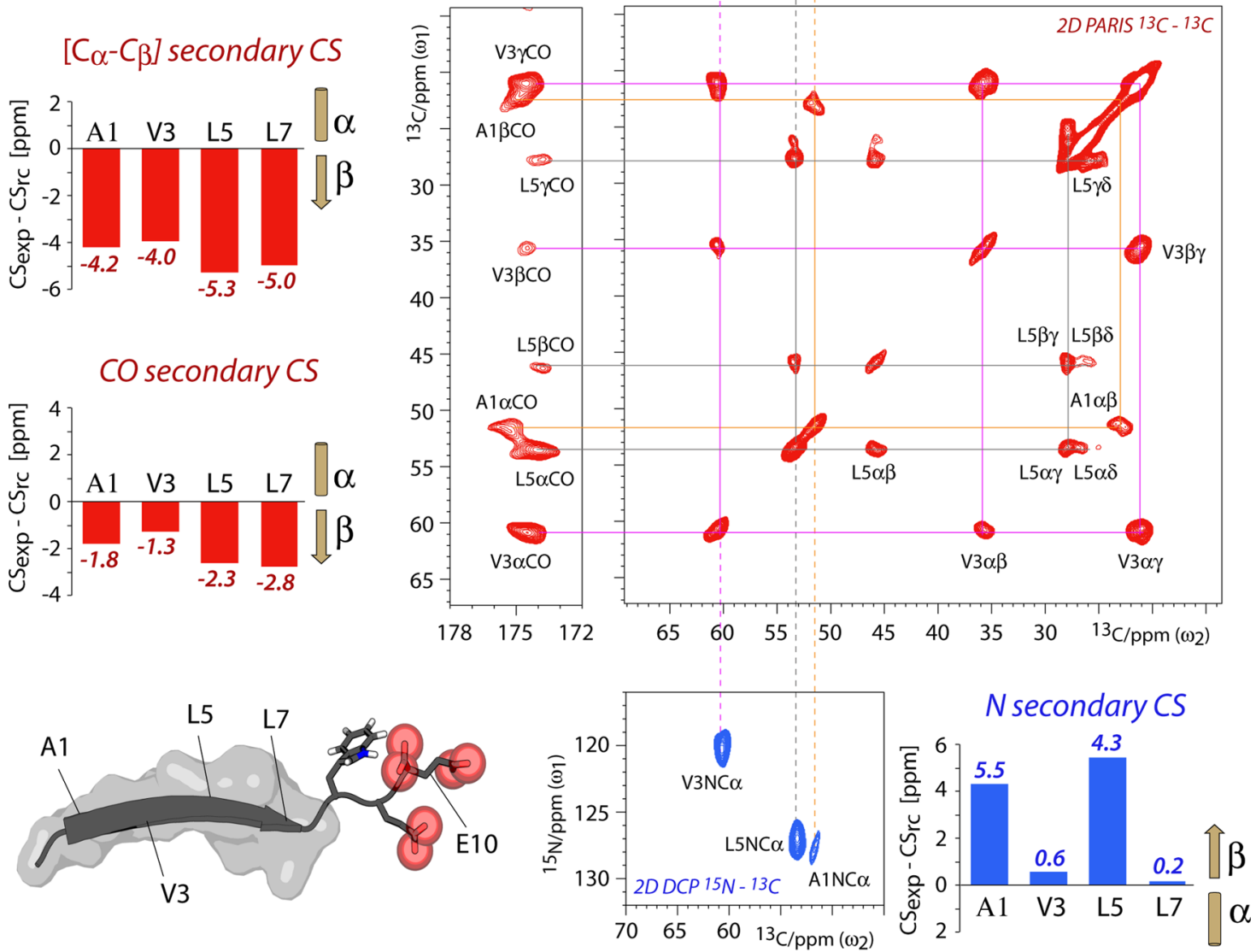

Figure 1. Solid-state NMR (ssNMR) experiments to determine SA2 nanovesicle secondary structure at high-resolution. $2 \mathrm{D}{ }^{1} \mathrm{H}-{ }^{13} \mathrm{C}$ FSLG ${ }^{18}$ (top right panel, colored in green), $2 \mathrm{D}{ }^{13} \mathrm{C}-{ }^{13} \mathrm{C}$ PARIS ${ }^{19,20}$ (middle right panel, red) and $2 \mathrm{D}{ }^{15} \mathrm{~N}-\mathrm{C}_{\alpha}$ SPECIFIC CP ${ }^{21}$ (bottom right panel, blue) ssNMR experiments were applied to $\left[{ }^{13} \mathrm{C},{ }^{15} \mathrm{~N}\right]-\mathrm{A} 1, \mathrm{~V} 3, \mathrm{~L} 5$ (construct $A$ ) and $\left[{ }^{13} \mathrm{C},{ }^{15} \mathrm{~N}\right]-\mathrm{A} 1, \mathrm{~L} 7, \mathrm{E} 10$ (construct B) site-specifically labeled SA2 nanocarriers. SSNMR spectra of construct B are shown in Figure S2. Analysis of secondary chemical shifts clearly indicated $\beta$-strand conformation for the hydrophobic residues. This was supported by a CD spectrum (top left panel). Residue E10 was invisible in dipolar-based experiments. A model of the SA2 secondary structure derived from ssNMR measurements is shown in the bottom left corner. All data (ssNMR and CD) were acquired at $10 \mathrm{mg} / \mathrm{mL} \mathrm{SA2}$ peptide concentration.

local and supramolecular organization of SA2 nanocarriers at the atomic level. Notably, we demonstrate that SA2 peptides in mature nanovesicles adopt an antiparallel and interdigitated organization that strongly diverges from the common organization of phospholipids in liposomes. The herein presented approach allows studying peptide-based nanovesicles at physiological conditions and at high-resolution, an important advance toward the tailoring of such materials for medial applications.

\section{RESULTS AND DISCUSSION}

High-Resolution Geometry of Assembled SA2 Peptides Revealed by Solid-State NMR Experiments. Solidstate NMR (ssNMR) provides atomic level structural information and is not curtailed by an intrinsic molecular size limit or sample heterogeneity, which renders the technique uniquely suited to characterize higher order aggregates such as peptide-based nanoparticles. ${ }^{22-26}$ In general, NMR chemical shifts are very sensitive to the local conformation. This offers a means to derive peptide secondary structure information at residue-level from the so-called "secondary chemical shifts" that compare observed chemical shifts with random coil values and exhibit opposite arithmetic signs for $\alpha$-helical and $\beta$-strand backbone conformations. ${ }^{27}$

Solid-state NMR experiments were performed with solidphase synthesized SA2 peptides that were $\left[{ }^{13} \mathrm{C},{ }^{15} \mathrm{~N}\right]$-isotope labeled at strategic positions. Two different labeling schemes (A1, V3 and L5 in construct A; A1, L7 and E10 in construct B) were used to provide secondary structure information for the entire peptide and to allow unambiguous assignments. Moreover, both constructs included one common label (A1) 
to ensure the comparison of identical peptide conformations. The labeled peptides spontaneously assembled at a concentration of $10 \mathrm{mg} / \mathrm{mL}(8.5 \mathrm{mM})$ in phosphate buffered saline, which led to the formation of a colloidal suspension. In agreement with our previous studies, this sample preparation consisted of spherical SA2 nanovesicles, which was verified by atomic force microscopy (AFM) measurements (Figure S1). Several ssNMR experiments (2D ${ }^{13} \mathrm{C}-{ }^{13} \mathrm{C}$ PARIS, ${ }^{19,20}$ 2D ${ }^{1} \mathrm{H}-{ }^{13} \mathrm{C}$ FSLG ${ }^{18}$ and $2 \mathrm{D}{ }^{15} \mathrm{~N}-{ }^{13} \mathrm{C}_{\alpha}$ SPECIFIC $\mathrm{CP}^{21}$ experiments) were acquired to characterize the secondary structure in SA2 nanovesicles (Figures 1 and S2). All experiments yielded well-resolved spectra that allowed straightforward identification of the spin systems of the labeled hydrophobic residues (A1, V3, L5, L7) for which we could obtain extensive $\left(\mathrm{CO}, \mathrm{C}_{\alpha}, \mathrm{H}_{\alpha}\right.$, $\mathrm{C}_{\beta}, \mathrm{N}$ ) assignments (Table 1). Signals of residue E10 were

Table 1. Solid-State NMR Chemical Shifts ${ }^{a}$

$\begin{array}{cccccc}\text { residue } & \mathrm{CO} & \mathrm{C} \alpha & \mathrm{H} \alpha & \mathrm{C} \beta & \mathrm{N} \\ \text { A1 } & 175.6 & 51.6 & 4.6 & 22.2 & 127.8 \\ \text { V3 } & 174.5 & 60.6 & 4.7 & 35.4 & 120.2 \\ \text { L5 } & 174.0 & 53.5 & 5.1 & 45.8 & 127.0 \\ \text { L7 } & 173.9 & 53.7 & 4.8 & 45.7 & 121.7 \\ \text { E10 } & \text { no internuclear signals in dipolar experiments } & \end{array}$

${ }^{a}$ All values are in ppm and were measured at $500 \mathrm{MHz}{ }^{1} \mathrm{H}$-frequency and $9.1 \mathrm{kHz}$ MAS. For $\mathrm{Al}$ and $\mathrm{L} 7 \mathrm{CO}$, the indicated values represent an unweighted average of the observed conformations.

invisible in dipolar-based experiments, which suggests that the negatively charged C-terminus exhibits fast dynamics ( $\mu$ s and faster). Indeed, signals of E10 could be detected at low sample temperature $(235 \mathrm{~K})$ with dipolar-based experiments and at higher temperature $(278 \mathrm{~K})$ by using direct ${ }^{13} \mathrm{C}$ excitation instead of dipolar cross-polarization transfer, demonstrating the high mobility of the peptide C-terminus (Figure S3) at physiological temperatures. Using published random coil average chemical shifts as reference, ${ }^{28}$ the calculation of secondary chemical shifts unanimously predicted $\beta$-strand conformation for residues A1, V3, L5 and L7 (Figure 1), strongly suggesting that residues $\mathrm{A} 1-\mathrm{L} 7$ adopt a continuous $\beta$ strand. This result could be confirmed (Figure S4) by the CSI 2.0 program $^{29}$ that connects chemical shifts and sequence data to determine secondary structure with an accuracy (about 90\%) that is comparable to structure-based methods such as DSSP. ${ }^{30}$ Moreover, a high content of $\beta$-strand secondary structure in SA2 nanocarriers is in agreement with circular dichroism (CD) measurements, which showed the typical profile of an extended secondary structure (Figure 1, top left panel).

The absence of peak doubling for residues V3 and L5 indicates that the hydrophobic core of the SA2 nanovesicles is relatively ordered (average $C_{\alpha}$ line width $=1.1 \pm 0.1 \mathrm{ppm}$ ). Peak doubling was however observed for L7CO and all A1 carbon signals. Indeed, for $\mathrm{Al}$, the $\mathrm{C}_{\beta}$ and $\mathrm{CO}$ signals showed at least two clearly distinguishable conformations, which could be detected in both constructs $\mathrm{A}$ and $\mathrm{B}$, although with slightly different populations and chemical shifts. The A1 ${ }^{13} \mathrm{C}$ chemical shifts were also different for a second batch of construct $A$ (Figure S5), which indicates that the conformation of the $\mathrm{N}$ terminus is sensitive to subtle details of the sample preparation. The L7CO signal also showed two different peaks (174.5 and $173.2 \mathrm{ppm}$ ), while the L7 side chain exhibited both peak doubling and generally weak signal intensities. Note that all A1 and L7 conformations feature chemical shifts that are indicative of extended secondary structure. Hence, the ssNMR measurements reveal the local geometry in the assembled nanocarrier at atomic level, demonstrating that the hydrophobic core A1-L7 of peptides exhibits $\beta$-strand conformation, while the anionic $\mathrm{C}$ terminus is mobile. Moreover, the experiments show that the local structure of SA2 nanovesicles is moderately disordered, with the heterogeneity increasing toward the $\mathrm{N}$ - and C-termini of the peptides.

Supramolecular Organization of SA2 Nanocarriers. To get insights into the assembly pathway and the higher order architecture of SA2 nanovesicles, we integrated the ssNMR secondary structure information with molecular dynamics (MD) simulations. On the basis of light scattering measurements, which show an average molecular weight of $>5 \mathrm{MDa}$ for SA2 nanocarriers (see also Supporting Information), a single spherical assembly should comprise several thousand peptides. The simulation of such large systems on the a priori unknown time scale of peptide self-assembly is very challenging. Moreover, the simulated system should be sufficiently dilute since the peptide concentration may modulate the assembly pathway. ${ }^{2,31-33}$ To meet these demanding requirements and yet to obtain high-resolution information on SA2 nanovesicles, we resorted to a sequential multiscaling approach, in which a very large and very long ( 3.4 million beads, $54 \mu$ s trajectory) coarse-grained (CG) simulation was connected in a series with a large and long (2.1 million atoms, $1 \mu$ s trajectory) atomistic simulation. The computations were supplemented by various experimental measurements to assess and verify the supramolecular organization and the morphology of the simulated assemblies.

The initial coarse-grained simulation step was carried out with the established MARTINI force field, ${ }^{34}$ which was recently successfully applied to study the self-assembly pathway of amphiphilic peptides into nanofibers and to investigate the assembly of diphenylalanine peptides. ${ }^{31,35}$ SSNMR experiments are an ideal complement to MARTINI since peptide secondary structure needs to be assigned at the beginning of the simulation and remains constant over the trajectory. On the basis of the ssNMR data, residues A2-L7 were assigned as $\beta$ strand, similarly to W8 that links the hydrophobic and the hydrophilic peptide parts. To implicitly simulate the neutral acetylated $\mathrm{N}$-terminus, which is not represented as an individual CG bead, we assigned A1 as a polar coil residue. Since the ssNMR experiments suggest that the anionic Cterminus is highly mobile, residues E9 and E10 were also assigned as coil. The glutamate side chains were deprotonated and charged, so as to simulate the peptides at neutral $\mathrm{pH}$ value. To set up the CG simulation system, 2500 SA2 peptides, randomly distributed, and 3.4 million CG water molecules were packed into a cubic box with a side length of $74.4 \mathrm{~nm}$, corresponding to a peptide concentration of approximately 10 $\mathrm{mM}$. This concentration is very close to the concentrations used in the ssNMR and AFM experiments. $\mathrm{Na}^{+}$and $\mathrm{Cl}^{-}$ions were added to neutralize the system and to mimic a $150 \mathrm{mM}$ $\mathrm{NaCl}$ solution. The total system comprised 3.47 million CG beads and was simulated over $54 \mu$ s at $300 \mathrm{~K}$ (Figure 2a and Movie S1). To best of our knowledge, this is the largest and longest reported simulation of a peptide-based nanoparticle to date. Over the course of the total trajectory, the peptides assembled into nine large nanoparticles, many of which comprised several hundred peptides. Depending on the progress of the simulation and the number of peptides involved, the particles adopted typical morphologies, from 

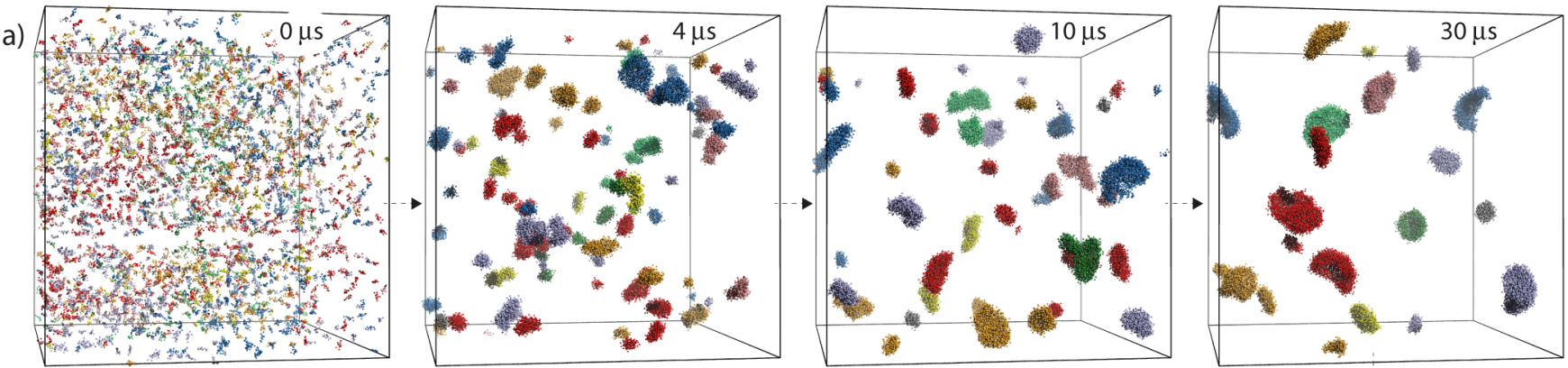

b) 1

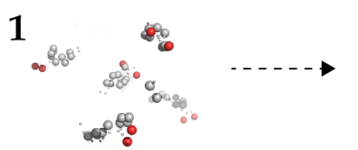

\section{5}

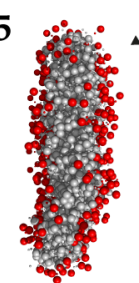

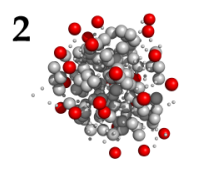
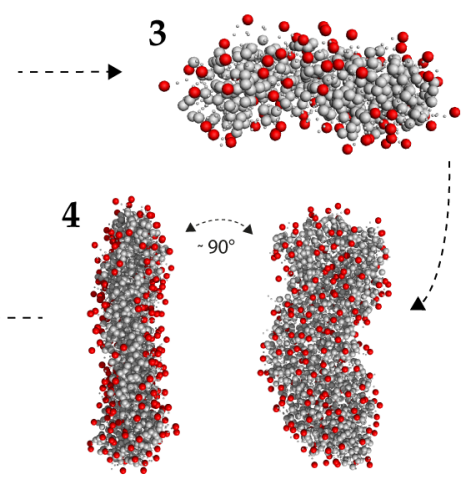

c)

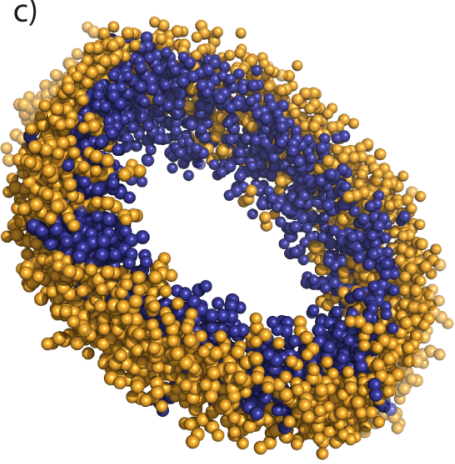

slice through the hemisphere

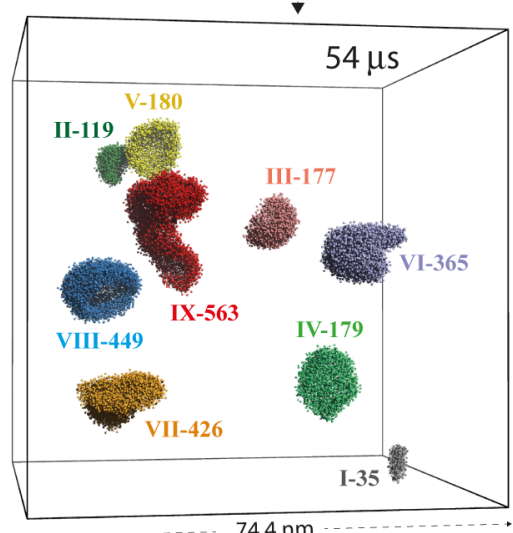

d)

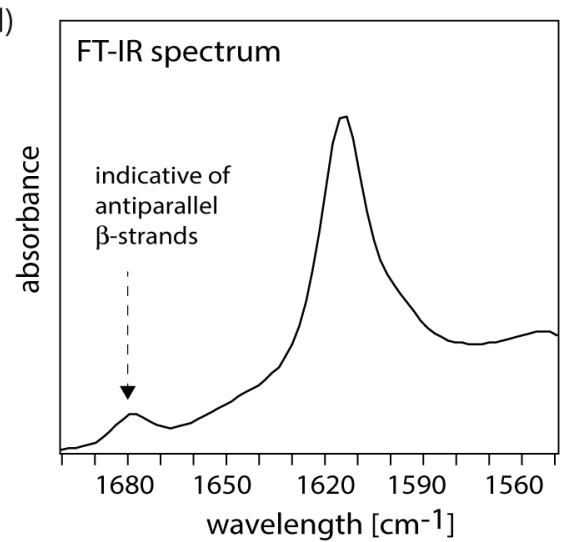

Figure 2. The assembly pathway and the supramolecular organization of SA2 nanocarriers. (a) 2500 SA2 peptides were evolved over $54 \mu$ s in a large cubic (74.4 nm side length) water-filled box using the MARTINI coarse-grained force field. Peptides that assembled in the same cluster after $54 \mu \mathrm{s}$ are depicted in the same color over the course of the trajectory. A small assembly of seven peptides was left out for clarity. (b) The assembly pathway of SA2 peptides, derived from CGMD simulations: Free peptides (1) assemble over micelle-like drops (2) to strings (3), followed by bilayer-like tiles (4), disks (5) and finally hemispheres (6). The hemisphere intermediate 6 shows Fragment VIII of (a). The negatively charged residues (E9 and E10) of the peptides' C-termini are colored in red. The $2.4 \mathrm{~nm}$ distance relates to the average separation between the backbone beads of residues E10 in opposing peptide layers. (c) Peptides organize in antiparallel $\beta$-sheets in which the hydrophobic parts align, resulting in interdigitated peptide bilayers. Peptides with opposing C-termini are colored in orange and blue. (d) The presence of a characteristic signal at $1680 \mathrm{~cm}^{-1}$ in FT-IR experiments confirms the antiparallel organization of peptides in SA2 nanocarriers.

which we inferred the assembly pathway (Figure $2 b$ ), which in many aspects resembles the self-assembly pathway of liposomes. $^{36}$ Within the first $2 \mu$ s of the simulation, free SA2 peptides (Figure $2 b$, intermediate 1 ) quickly assembled to small ( $<25$ peptides) disordered micelles with a water-free core (intermediate 2), which grew further to elongated micelle-like strings ( $<60$ peptides, intermediate 3 ) within the first $5 \mu$ s. These strings with an oil-like interior transformed, with increasing size of the assemblies and duration of the simulation, to tiles $(<200$ peptides) reminiscent of lipid bilayers (intermediate 4). The tiles further evolved, without necessitating further particle-fusion events, toward circular disks with laterally even peptide distributions to minimize the peptide/ water surface (intermediate 5). These disks finally merged into larger nanoparticles that exhibit a notable curvature, reminiscent of hollow hemispheres (intermediate 6), which presumably represent the onset of SA2 nanocarriers. Formation of closed nanocarriers was not observed at this time scale, but is anticipated to take milliseconds at the given MD settings and peptide concentration, something that would be computationally too expensive to demonstrate by CGMD. Note that the $\mathrm{SA} 2$ intermediates of Figure $2 \mathrm{~b}$ were selected from the trajectory to enhance the clarity of the representation of the 
assembly pathway. The actual assembly pathway of particles can be followed in Movie S1.

In analogy to liposomes (lipid bilayers), amphiphilic peptidebased nanovesicles are assumed to form bilayer constructs $1,16,17$ often referred to as peptosomes, in which the hydrophobic peptide termini arrange tail-to-tail and the charged termini (the "headgroups") are exposed to bulk water. As expected from this concept, the surface of simulated SA2 nanoparticles is decorated with the C-terminal negatively charged glutamate residues (Figure $2 b$, in red). However, the wall (bilayer) thickness of CG SA2 nanoparticles amounts on average to a mere $24 \AA$ (Figure $2 \mathrm{~b}$, intermediate 6). This speaks against a tail-to-tail arrangement of peptides, which would likely result in a thicker wall, given that the average $\mathrm{C}_{\alpha}$ to $\mathrm{C}_{\alpha+2}$ distance in straight $\beta$-strands is about $6 \AA$, implying that the $\beta$-strand A1L7 already comprises $18 \AA$. For comparison, Zhang et al. assumed a peptide length of $20 \AA$ (and a bilayer thickness of 40 $\AA)$ for an eight-residue $\beta$-strand surfactant-like peptide. ${ }^{1}$ Indeed, further analysis on the organization of the CG SA2 nanoparticles revealed a notable degree of interdigitation, i.e., that the hydrophobic peptide tails of opposite peptide layers overlap and arrange as antiparallel $\beta$-strands (Figure 2c). This result could be reproduced in a well-equilibrated $100 \mu \mathrm{s}$ CGMD simulation of $120 \mathrm{SA} 2$ peptides in a periodic bilayer slab (Figure S6). Interestingly, such an interdigitated arrangement of amphiphilic peptides was also proposed in a computational study of $\mathrm{A}_{3} \mathrm{~K}$ nanotubes. ${ }^{37}$

We used Fourier transform infrared spectroscopy (FT-IR) to validate this surprising finding. The experimental validation of the simulated peptide arrangement is especially important, given that $\beta$-sheet formation might not be very accurately modeled in MARTINI due to the missing hydrogen-bond directionality. The relative direction of $\beta$-strands can be assessed by FT-IR based on the analysis of the amid I band region $\left(1700-1600 \mathrm{~cm}^{-1}\right)$, which, as demonstrated in several studies, exhibits an additional signal around 1695-1675 $\mathrm{cm}^{-1}$ in the presence of antiparallel $\beta$-sheets. ${ }^{22,38,39}$ This additional band could be clearly detected in our measurements (Figure $2 \mathrm{~d}$ ), which strongly corroborates that SA2 nanocarriers are formed of interdigitated antiparallel $\beta$-strands. Hence, our study strongly indicates the build of SA2 nanocarriers substantially diverges from phospholipid liposomes.

Supramolecular Structure of SA2 Nanocarriers. While the CGMD simulations offered striking insights into the supramolecular organization of SA2 nanovesicles, a CG representation does in general not provide the precision or resolution of atomistic simulations. We especially worried that the large spatial dimensions of MARTINI water molecules and ions, which are $\geq 4$ times larger than their atomistic equivalents, could distort the interaction of these molecules with the waterexposed anionic peptide C-termini. To simulate SA2 nanoparticles in a more accurate (and computationally more expensive) atomistic representation, we first compared several atomic force fields for their aptitude using a system of 60 randomly distributed SA2 peptides (Figure S7). In agreement with our ssNMR data, modern force fields (AMBER ff99SBILDN, ${ }^{40}$ GROMOS54a $7^{41}$ ) consistently showed stable $\beta$-sheet formation, while older versions (AMBER $\mathrm{ff} 99^{42}$ ) yielded spurious $\alpha$-helical peptides, which explains the outcome of previous computational studies. ${ }^{43}$ Accordingly, the GROMOS54a7 force field was used for all following atomistic simulations.
The 2500 peptides and the ions after $54 \mu$ s of CGMD simulation were transformed to atomic coordinates using the BACKWARD tool, ${ }^{44}$ which was slightly modified to include an atomistic representation of the acetylated peptide N-terminus. The system, which comprised 41 million atoms after rehydration, was briefly equilibrated (see Materials and Methods) and then freely evolved over 37.5 ns. From the end point of this simulation, a nanoparticle of 449 assembled peptides (fragment VIII in Figure 2a) was further simulated in a smaller box $(2.1$ million atoms in a cubic box of $28 \mathrm{~nm}$ side length) for $1 \mu \mathrm{s}$. The peptide assemblies were stable in the atomistic representation; however, the curvature of hemispheric particles rapidly decreased, which implies an increase in the radius of the SA2 nanocarriers (see also Movie S2). An estimated guess of the size of closed SA2 nanocarriers in CGMD simulations suggests a sphere-diameter of about $13 \mathrm{~nm}$ (Figure 3a). While it is complicated to infer the nanocarrier size

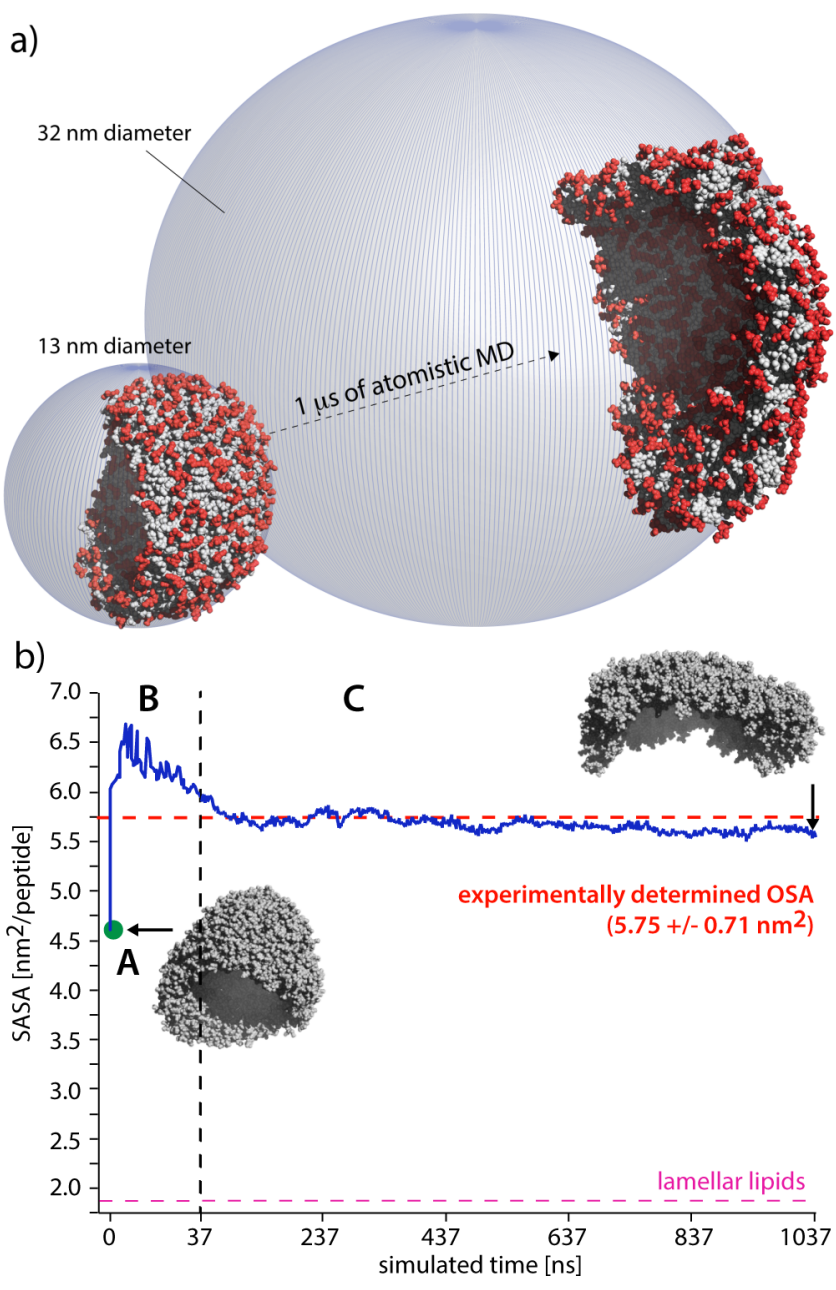

Figure 3. Remodeling of SA2 nanocarrier curvature. (a) The curvature of hemispheric SA2 fragments (left) substantially decreases when subjected to atomistic simulations (right). This implies that CGMD simulations underestimate the size of SA2 nanocarriers. (b) Comparison of the occupied surface area (OSA) measured by static light scattering (SLS) and the solvent accessible surface area (SASA) derived from $\mathrm{MD}$ simulations. Point $\mathrm{A}$ (in green) is the starting system of the atomistic simulation (comprising 2500 SA2 peptides), backtransformed from the CGMD simulation. This system was evolved for $37.5 \mathrm{~ns}$, shown in passage B. In passage C, an assembly of 449 peptides was further evolved for $1 \mu \mathrm{s}$. 
from our atomistic MD simulations due the difficulty to extrapolate from a fragment to the closed vesicle (and due to the lack of statistics), we estimate that the diameter of SA2 nanocarriers is at least $32 \mathrm{~nm}$ in the atomistic representation (i.e., 2.5 times larger than in the CG model). Remarkably, the larger spheres that we observe in the atomistic MD simulations are in agreement with the SA2 vesicle diameter of $20-60 \mathrm{~nm}$ that we observe by AFM (see Figure S1) and that was observed by cryo-TEM. ${ }^{26}$ The larger particle size is also in line with light scattering measurements, which show a hydrodynamic radius of $32 \mathrm{~nm}$ for SA2 nanovesicles (Table S1). The CGMD simulation however appears to underestimate the nanovesicle size, although it might be that the smaller diameter of the CG particles reflects surface tension effects and might increase to the experimental value if the system was given more time to equilibrate and form closed vesicles, which would however be very costly to simulate at the given peptide concentration. Moreover, considering the good agreement of the converted all-atom model with experimental data, we are confident that our model already gives a good approximation of the organization of SA2 nanocarriers.

On a molecular level, a change in particle curvature necessitates a rearrangement in the packing density of the peptides. To infer these changes and to validate the curvature flattening in atomistic simulations, we followed the solvent accessible surface area (SASA) of the simulated peptide assemblies over time and compared it to an experimentally determined occupied surface area (OSA) (Figure 3b). OSA represents the average area projected onto the lateral plane of the peptide assembly and often will be slightly smaller than the SASA, due to out-of-plane fluctuations of the peptide molecules and surface convolution. Using static light scattering measurements, we calculated an OSA/peptide of $5.75 \pm 0.71 \mathrm{~nm}^{2}$ (see Materials and Methods), which is astonishingly large in comparison to liposomes, for which the OSA/lipid is less than $1.0 \mathrm{~mm}^{2}$ and the SASA/lipid amounts to less than 2.0 $\mathrm{nm}^{2}{ }^{45,46}$ In comparison to the experimental data, the SASA of the back-transformed SA2 particles (after $54 \mu \mathrm{s}$ of CGMD simulation) is significantly lower with $4.6 \mathrm{~nm}^{2} /$ peptide (point A in Figure $3 \mathrm{~b}$ ). However, within the first nanoseconds of the atomistic simulation, the SASA leaps to a peak of $6.7 \mathrm{~nm}^{2}$ / peptide and then slowly decreases until it reaches a plateau at $5.6 \mathrm{~nm}^{2} /$ peptide after $400 \mathrm{~ns}$, which is stable for the remainder of the simulation. A second atomistic simulation over $1 \mu$ s with a nanoparticle of 179 peptides (fragment IV in Figure 2a) came to a comparable result of $5.9 \mathrm{~nm}^{2} /$ peptide. The slightly larger SASA of the smaller particle is accountable for by the larger contribution of edge effects to the surface. Hence, this analysis revealed an excellent match between computed (from the atomistic model) SASA and experimental OSA. This corroborates that our atomistic simulations capture a realistic representation of the molecular surface structure and the organization of SA2 nanocarriers.

The sudden leap of the SASA at the beginning of the atomistic simulation suggests a substantial reorganization of the nanocarrier surface. In both CGMD and atomistic simulations, the anionic surface is extensively screened by counterions (Figure 4a). However, while the large $\mathrm{CG} \mathrm{Na}^{+}$beads remain on top of the surface, $\mathrm{Na}^{+}$ions intercalate between the anionic peptide C-termini. The radial distribution function $g(r)$ between SA2 peptides and $\mathrm{Na}^{+}$ions exhibits a primary ion shell at short distance $(<3 \AA)$ which indicates direct peptide$\mathrm{Na}^{+}$interactions, (Figure $4 \mathrm{~b}$ ), as well as a secondary ion shell at
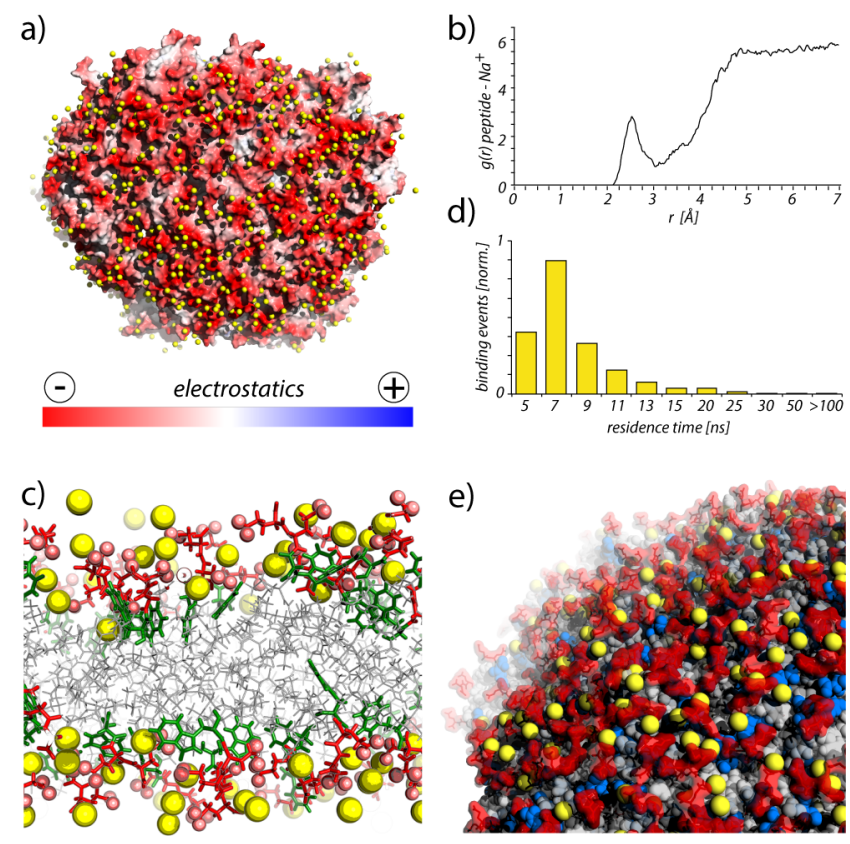

Figure 4. The surface structure of SA2 nanovesicles. Data were derived from the $1 \mu \mathrm{s}$ atomistic simulations with 449 peptides. (a) The electrostatic surface of SA2 nanocarriers is strongly negatively charged and screened by $\mathrm{Na}^{+}$ions (in yellow). (b) The radial distribution function between $\mathrm{Na}^{+}$ions and SA2 peptides shows a primary shell of direct peptide-ion coordination. (c) $\mathrm{Na}^{+}$ions deeply intercalate between the C-terminal glutamate residues (red) and are bordered by tryptophan residues (green). (d) Evaluation of the residence time of $\mathrm{Na}^{+}$ions of the primary shell at the nanocarrier surface. (e) The vesicle surface exhibits a pattern of protruding glutamate spikes (red) and spacious cavities, in which $\mathrm{Na}^{+}$ions reside (yellow). Cavities are further widened by peptide $\mathrm{N}$-termini (blue) that span the entire nanocarrier wall. These cavities explain the large OSA observed in experiments.

longer distance which represents water-mediated interactions. Cations of the primary shell often deeply penetrate into the nanocarrier wall (Figure 4c), which accounts for the curvature flattening in atomistic simulations. Initially, after back-transformation, the anionic C-termini of peptides are too tightly packed and repel each other, resulting in the sudden SASA leap. This is followed by the intercalation of $\mathrm{Na}^{+}$ions, which increases the "headgroup" area and thereby counterbalances the curvature induced by the conic hydrophobic N-termini. However, although $\mathrm{Na}^{+}$ions inserted deeply into the carrier wall, their residence times were relatively short $(<10 \mathrm{~ns}$ on average), which points to a dynamic vesicle surface (Figure $4 d$ ). The large SASA, in turn, results from the strong degree of peptide interdigitation in SA2 nanocarriers, leading to protruding anionic C-termini that stick out of the vesicle wall like spikes. These spikes electrostatically repel each other, resulting in spacious shallow cavities that are filled with weakly bound hydrated cations (Figure 4e) and account for the large SASA/peptide of SA2 nanocarriers. The cavities are further widened by the necessity to accommodate the bulky tryptophan residues that follow the glutamates in the peptide sequence and by $\mathrm{N}$-termini of the opposite peptide layer which reach as far as the nanocarrier surface. Altogether, the SA2 surface structure is, if at all, only distantly related to common phospholipid liposomes.

The SA2 nanocarrier surface described by integrating ssNMR data with multiscale simulations is in agreement with atomic 
level (ssNMR) and global structural data (light scattering, FTIR). Since the surface structure is a function of the interdigitated peptide arrangement, a well-described surface suggests a reasonable organization of the nanocarrier wall. Indeed, a quantitative analysis of secondary structure revealed a good consistency between the local geometry of the simulated vesicle wall and the ssNMR data (Figure 5a). The hydrophobic

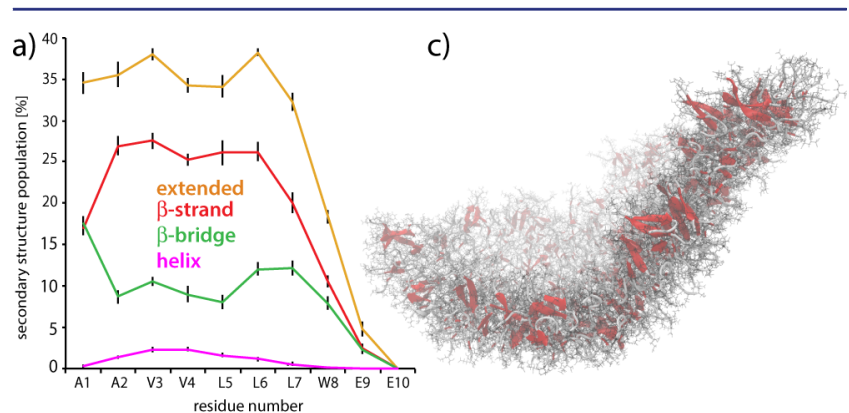

b) contact matrix
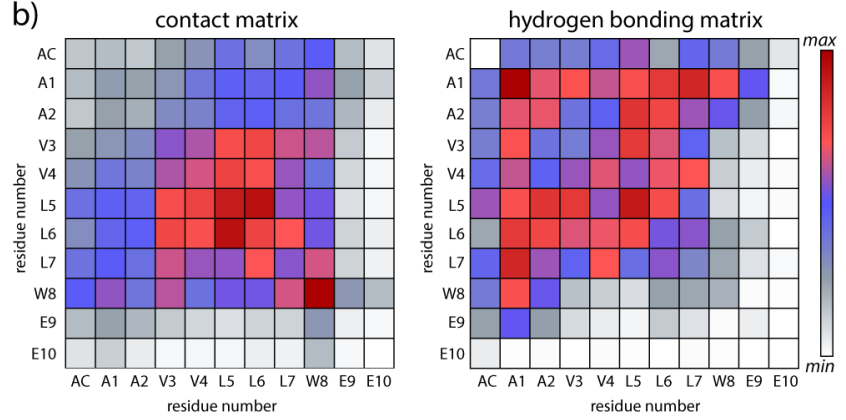

Figure 5. Interactions among SA2 peptides. Data were derived from the atomistic simulation of 449 peptides over $1 \mu \mathrm{s}$. (a) Residue-specific secondary structure propensity, averaged over the last $50 \mathrm{~ns}$ of the simulation. Black bars indicate the standard deviation. Extended secondary structure comprises $\beta$-strand and $\beta$-bridge, while helix comprises $\alpha$-, $3_{10^{-}}$and $\pi$-helical elements. (b) (Left) Intermolecular contact map using a distance cutoff of $4 \AA$ and (right) intermolecular hydrogen bonding map using a simple $4 \AA$ distance donor (backbone nitrogen)-acceptor (backbone oxygen) criterion. Both maps were averaged over the final $50 \mathrm{~ns}$ of the simulation. (c) A snapshot of the nanoparticle after $1 \mu \mathrm{s}$. Extended secondary structure elements are shown in red. See Figure S10 for other perspectives of the vesicle and a zoom into the nanocarrier wall.

core A1-L7 showed a pronounced $(33-38 \%)$ population of extended conformation, which then sharply decreased toward the C-terminus. The C-terminus E10 did not adopt any secondary structure and, in particular, exhibited strongly increased dynamics (Figure S8) in comparison to residues A1-L7. This explains the absence of E10 in dipolar-based spectra. As a next step, we derived intermolecular interaction maps from the simulations (Figure $5 b$ ) to study which forces govern the nanocarrier interior. These matrices represent the absolute number of contacts (contact matrix) as well as polar contacts and hydrogen bonding (hydrogen bonding matrix). The contact matrix evidences that the nanovesicle core is dominated by hydrophobic clustering between residues V3-L7 and that peptide-peptide interactions are largely restricted to residues A1-W8. It is further visible that the $\mathrm{N}$-terminal alanine residues feature most contacts with $\mathrm{C}$-terminal residues, which results from the antiparallel peptide arrangement. Moreover, tryptophan residues, organized in two belts (Figure 4c), heavily interact with each other, which is presumably favored by attractive electrostatics and packing effects between aromatic rings. As revealed by the hydrogen bonding matrix, the flipside of the interplay between bulky aromatic residues is their weak involvement in hydrogen bonding, which is a steric effect and only overcome by the slim alanine residues (of antiparallel peptides), which can squeeze into the aromatic belt. Generally, the alanine residues are active hydrogen bonding partners for parallel and antiparallel peptides. The simulations indeed indicate that interdigitated peptides form both antiparallel and parallel $\beta$-sheets and it is tempting to suggest that these two conformations, together with the lack of hydrogen bonds between bulky hydrophobic C-terminal residues, are responsible for the conformational heterogeneity observed in ssNMR experiments. Interestingly, while the hydrogen bonding maps showed hardly any backbone hydrogen bonds involving the glutamate residues, their carboxyl side chains extensively interacted with the W8 indole group (Figure S9), casting a kind of dynamical and loosely knit mesh at the vesicle surface.

A limitation of our analysis is the residual disorder in the system. A visual inspection (Figures 5c and S10) of the nanocarrier after $1 \mu \mathrm{s}$ of atomistic MD simulation showed large patches of up to $20-30$ connected $\beta$-strands, but also regions without ordered secondary structure. Hence, although this heterogeneity is somewhat corroborated by our ssNMR data, peptide motion is considerable restricted within $1 \mu \mathrm{s}$ and much longer simulations might presumably result in a more homogeneous and potentially more accurate $\beta$-sheet vesicle core. The homogeneity of the system may be improved by the incorporation of peptide-peptide ssNMR distance restraints. Such high-resolution data on the intermolecular peptide arrangement would presumably better define the molecular details of the peptide assembly and enhance our atomic level understanding of the supramolecular organization of SA2 nanocarriers, which is in our study rather based on data of global character. Experiments to derive such restraints were however impeded due to extensive spectral overlap of residues L5 and L7 in constructs A and B and by the general challenge to obtain sensitive NMR spectra of peptide-based nanovesicles. For example, the ${ }^{13} \mathrm{C}-{ }^{13} \mathrm{C}$ and ${ }^{15} \mathrm{~N}-{ }^{13} \mathrm{C}$ experiments to assign construct $B$ (Figure S2) already required 896 and 10400 scans, respectively, corresponding to $2 \mathrm{~d} 14 \mathrm{~h}$ and $3 \mathrm{~d} 17 \mathrm{~h}$ of measurement time. In future studies, it may be advantageous to use isotope labeling schemes ${ }^{47}$ that allow probing intermolecular contacts with more sensitive ${ }^{1} \mathrm{H}$-detected ssNMR experiments. Nevertheless, our study demonstrates that SA2 peptide nanocarriers are partially disordered and exhibit a highly dynamic surface. It is a particular strength of the combination of ssNMR and MD simulations to unravel and interpret such structural heterogeneity, which is presumably an important factor to consider for the rational design of peptidebased nanoparticles.

The knowledge on the atomic level geometry and dynamics of assembled peptides in relation to the supramolecular organization of the SA2 nanocarrier offers a number of starting points to tailor the biophysical properties of the vesicle such as its stability, surface texture or permeability. A promising lead could be the addition of a positive charge to the $\mathrm{N}$-terminus, which is likely to modify the degree of interdigitation. Either the removal of the $\mathrm{N}$-acetyl group (slim positive charge) or the replacement of the $\mathrm{N}$-terminal alanine residue for an arginine/ lysine residue (bulky and flexible positive charge) is likely to further enhance interdigitation with a further thinning of the nanocarrier wall. Another lead could be the substitution of the tryptophan residue by a less bulky aromatic residue such as 
phenylalanine or tyrosine. This could allow a better alignment of peptide backbones for hydrogen bonding (Figure $5 b$ ), enhance the hydrogen bonding activity of the C-terminal residues that precede the glutamates and thereby reduce structural heterogeneity and the high permeability of SA2 nanocarriers. ${ }^{48}$ Interestingly, while substitution to a tyrosine would allow for hydrogen bonds with the E9 and E10 carboxylgroups, phenylalanine would break these bonds (Figure S8) and thus modulate the surface properties of the nanocarrier. The latter is particularly interesting since control over the surface dynamics and order is crucial for peptide-based nanomaterials that present epitopes or act as templates in material sciences. ${ }^{2}$

\section{CONCLUSIONS}

Using an integration of several experimental techniques with large- and multiscale MD simulations, we have presented for the first time an atomic level model of the supramolecular organization of the multimega-Dalton SA2 peptide-based nanocarrier, which suggests several potential leads for the rational design and tuning of such systems. In particular, we could show that the SA2 nanocarrier organization does not involve liposome-like tail-to-tail orientation of the amphiphilic molecules. To the best of our knowledge, this is the first description of such an arrangement in peptide-based nanovesicles and speaks against the hitherto prevalent idea that "lipid-like" amphiphilic peptides organize like lipids on the supramolecular level. Further high-resolution studies will be necessary to judge to what extent our findings can be generalized to other peptide-based nanocarriers.

The here introduced approach should be of broad utility for studies on peptide-based nanomaterials at atomic level and at physiological conditions. Moreover, given that such nanomaterials are amenable to ssNMR, the level of detail could be readily expanded to peptide-water interactions ${ }^{49}$ and to quantitative high-resolution dynamics of the assembled peptides, ${ }^{50}$ which would provide further valuable information for the rational design of nanoscale drug delivery systems.

\section{MATERIALS AND METHODS}

Sample Preparation. Self-assembled peptide particles were prepared by dispersion of SA2 peptide powder ( $>95 \%$ purity, acquired from Genscript, USA) in phosphate buffered saline (PBS $=140 \mathrm{mM}$ $\mathrm{NaCl}, 13 \mathrm{mM} \mathrm{Na} \mathrm{HPO}_{4}$ and $2.5 \mathrm{mM} \mathrm{NaH} \mathrm{PO}_{4}$ [pH 7.4]) (Braun Melsungen AG, Germany) using bath sonication. SA2 peptide powder (according to the final concentration, e.g., $8.4 \mathrm{mg}$ peptide powder for a $10 \mathrm{mM}$ sample) was hydrated with $40 \mu \mathrm{L}$ of $0.2 \mathrm{M} \mathrm{NaOH}$. After each step, peptide dispersion was ultrasonicated in a water bath for $5 \mathrm{~min}$ at $30^{\circ} \mathrm{C}$. Before reaching final volume, the $\mathrm{pH}$ was adjusted to 7.4 by 0.2 $\mathrm{M} \mathrm{HCl}$. The final dispersion was incubated overnight at $25^{\circ} \mathrm{C}$ to reach equilibrium. The peptide concentration in the solution was measured by UV-spectrophotometry using a tryptophan extinction coefficient of $5500 \mathrm{M}^{-1} \mathrm{~cm}^{-1}$. According to this procedure, samples with appropriate concentrations were prepared and applied for CD $(10 \mathrm{mg} / \mathrm{mL})$, AFM ( 2 and $10 \mathrm{mg} / \mathrm{mL})$, FT-IR $(2 \mathrm{mg} / \mathrm{mL})$, DLS $(0.6,0.8,1$, and $2 \mathrm{mg} /$ $\mathrm{mL})$ and SLS analysis $(0.6,0.8,1 \mathrm{mg} / \mathrm{mL})$. For the ssNMR measurements, labeled peptides (construct $\mathrm{A}:{ }^{13} \mathrm{C},{ }^{15} \mathrm{~N}$-labeled at $\mathrm{Al}$, V3, L5, purity $>90 \%$, acquired from JPT Peptide Technologies GmbH, Germany ; construct B: ${ }^{13} \mathrm{C},{ }^{15} \mathrm{~N}$-labeled at $\mathrm{A} 1, \mathrm{~L} 7, \mathrm{E} 10$, purity $>95 \%$, acquired from New England Peptide) were dispersed in PBS to a concentration of $10 \mathrm{mg} / \mathrm{mL}$ according the mentioned procedures.

Solid-State NMR Spectroscopy. Experiments were carried out at a magnetic field of $11.7 \mathrm{~T}$ ( $500 \mathrm{MHz}{ }^{1} \mathrm{H}$-frequency) at $9.1 \mathrm{kHz}$ Magic Angle Spinning (MAS) frequency and $278 \mathrm{~K}$ sample temperature. ${ }^{13} \mathrm{C}$ and ${ }^{15} \mathrm{~N}$ chemical shifts were calibrated using Adamantane and tripeptide AGG as external references, respectively. ${ }^{51,52}$ The ${ }^{1} \mathrm{H}$ signal of Adamantane was used to reference ${ }^{1} \mathrm{H}$ chemical shifts. The $2 \mathrm{D}$ ${ }^{13} \mathrm{C}-{ }^{13} \mathrm{C}$ PARIS ${ }^{19}$ experiments $(N=0.5$, i.e., phase inversion after 55 $\mu \mathrm{s}$ ) were performed with $30 \mathrm{~ms}$ mixing time and a recoupling amplitude of $8 \mathrm{kHz}$. A short cross-polarization contact time of $125 \mu \mathrm{s}$ was used in the $2 \mathrm{D}{ }^{1} \mathrm{H}-{ }^{13} \mathrm{C}$ FSLG experiments. ${ }^{18} \mathrm{~A}{ }^{1} \mathrm{H}-{ }^{1} \mathrm{H}$ FSLG decoupling amplitude of $90 \mathrm{kHz}$ was applied in the indirect dimension. FSLG measurements with ${ }^{13} \mathrm{C},{ }^{15} \mathrm{~N}$ Valine and additional ${ }^{1} \mathrm{H}-{ }^{13} \mathrm{C}$ HECTOR experiments with SA2 peptides (at $13 \mathrm{kHz}$ MAS, see Figure S11) were carried out to get the correct ${ }^{1} \mathrm{H}$ chemical shifts. $\mathrm{A}{ }^{15} \mathrm{~N}-{ }^{13} \mathrm{C}$ contact time of $3.5 \mathrm{~ms}$ was used in the $2 \mathrm{D}$ SPECIFIC $\mathrm{CP}^{21}$ experiments. Typical $90^{\circ}$ pulse lengths for the experiments on the peptide constructs were $3.8 \mu$ s for ${ }^{1} \mathrm{H}, 3.4 \mu$ s for ${ }^{13} \mathrm{C}$ and $8.5 \mu$ s for ${ }^{15} \mathrm{~N}$. Further acquisition and processing parameters can be found in the Supporting Information (Table S2).

Molecular Dynamics Simulations. Coarse-grained (CG) molecular dynamics (MD) simulation was carried out using the GROMACS simulations package version $4.5 .4^{53}$ and the MARTINI force field version $2.2^{34}$ together with an integration step of $20 \mathrm{fs}$ and the standard settings for nonbonded interactions in a NPT ensemble with period boundary conditions. Simulation times were multiplied by a factor of 4 to account for the smoothness of the CG potentials. The system was coupled to a pressure bath at 1 bar $\left(\tau_{\mathrm{p}}=0.5 \mathrm{ps}\right)$ and coupled $\left(\tau_{\mathrm{T}}=1.0 \mathrm{ps}\right)$ to a heat bath of temperature $300 \mathrm{~K}$. A fully extended SA2 peptide was used as starting structure, converted to CG representation using the martinize.py script and the secondary structure assigned from $\mathrm{Al}$ to E10 as CEEEEEEECC (E = Extended, $\mathrm{C}=\mathrm{Coil})$. The Al backbone bead was replaced by a polar P4 bead to mimic $\mathrm{N}$-acetylation. To build the CG starting simulation system, 2500 peptides were randomly distributed in a large, water-filled periodic and cubic box of $74.4 \times 74.4 \times 74.4 \mathrm{~nm}^{3}$ volume. $150 \mathrm{mM}$ $\mathrm{NaCl}$ and counterions were added to electrostatically neutralize the system. The total system comprised 2500 peptides, 3405700 water beads, $10000 \mathrm{Na}^{+}$beads and $2500 \mathrm{Cl}^{-}$beads and was evolved for 54 $\mu \mathrm{s}$. The computation was, on average, run on $450 \mathrm{CPUs}$, which yielded about $0.6 \mu \mathrm{s} /$ day of simulation time.

Atomistic MD simulations were carried out using the GROMOS54a7 force field of the GROMACS package. ${ }^{41}$ The CG system (expect for water molecules) after $54 \mu \mathrm{s}$ of simulation time was transformed to atomic coordinates. ${ }^{44}$ This included addition of the Nterminal acetyl-group. The system ( $>41$ million atoms) was rehydrated, equilibrated with position restraints and freely evolved for $37.5 \mathrm{~ns}$ at a temperature of $300 \mathrm{~K}$ (see Supporting Information for further details). Afterward, two nanoparticles (particles IV and VIII in Figure 2a) were further evolved for $1 \mu$ s (see Supporting Information for further details). On average, simulations were run on $550 \mathrm{CPUs}$, which yielded about $0.5 \mathrm{~ns} /$ day and $12 \mathrm{~ns} /$ day of simulations time for the full 41 million atoms system and the 449 peptides system, respectively. The STRIDE program was used to evaluate secondary structure. ${ }^{54}$ Protons were added to the peptides before calculations of peptide-peptide interactions matrixes. The peptide $-\mathrm{Na}^{+}$radial distribution function and the peptide SASA were calculated with standard GROMACS scripts (g_rdf and g_sas). $\mathrm{Na}^{+}$residence times were calculated using an in-house GROMACS analysis script (http:// zefiros.eu/confluence/display/ZS/Gromacs+Residence+Time+Tool).

Circular Dichroism Spectroscopy. Experiments were measured in a double beam DSM $1000 \mathrm{CD}$ spectrometer (Online Instrument Systems, Bogart, GA, USA) using a circular quartz cuvette of $0.5 \mathrm{~mm}$ path length (Hellma, Müllheim, Germany) and peptide dispersions in PBS ( $\mathrm{pH}$ 7.4). Five measurements of $1.0 \mathrm{~nm}$ increment were scanned from 250 to $180 \mathrm{~nm}$ at room temperature. The average of five spectra was subtracted from the buffer spectrum as the background.

Light Scattering Techniques. Particle size of the self- assemblies was measured in PBS by Dynamic Light Scattering (DLS) at $90^{\circ}$ on an ALV CGS-3 goniometer system (Malvern Instruments, Malvern, UK) equipped with a JDS Uniphase $22 \mathrm{~mW} \mathrm{He}-\mathrm{Ne}$ laser operating at $632.8 \mathrm{~nm}$, an optical fiber-based detector, a digital LV/LSE-5003 correlator and a temperature controller (Julabo water bath) to set different temperatures. Autocorrelation curves were analyzed using DTS 4.0 particle analysis software (Malvern, UK). The reported 
hydrodynamic radius is the $z$-averaged hydrodynamic radius as reported by the DTS 4.0 software. To get insight into the shape of particles and determine the occupied surface area (OSA) per peptide in the assemblies, static light scattering (SLS) analysis was performed. The experiment was operated at different scattering angles $\left(20-140^{\circ}\right)$ for three different peptide concentrations (600, 800, and $1000 \mu \mathrm{g}$ / $\mathrm{mL}$ ). A Zimm plot was constructed using ALVStat 4.31 software (ALV, Langen, Germany), and the molecular weight and the radius of gyration, using the $\mathrm{d} n / \mathrm{d} c(\sim 0.185 \mathrm{~mL} / \mathrm{g})$ of peptides in PBS, were obtained. See Supporting Information for further details.

Infrared Spectroscopy. ATR-FT-IR measurements were performed at ambient temperature on a PerkinElmer 2000 Fourier transform spectrometer equipped with a DTGS detector. To avoid the $\mathrm{H}_{2} \mathrm{O}$ absorption in the region $1600-1700 \mathrm{~cm}^{-1}$, PBS was prepared with $\mathrm{D}_{2} \mathrm{O}$ for peptide particle preparation. Spectra of a $2 \mathrm{mg} / \mathrm{mL}$ preparation of SA2 peptide were recorded with an ATR accessory (PIKE) equipped with a diamond crystal as the reflecting element. The optical resolution was $4 \mathrm{~cm}^{-1}$ and 30 scans were accumulated for one spectrum. Spectral interpretation was carried out after subtraction of the spectrum of PBS $\left(\mathrm{D}_{2} \mathrm{O}\right)$ as background.

\section{ASSOCIATED CONTENT}

\section{S Supporting Information}

AFM images of SA2 nanovesicles; ssNMR experiments of ${ }^{13} \mathrm{C},{ }^{15} \mathrm{~N}-\mathrm{A} 1, \mathrm{~L} 7, \mathrm{E} 10 \mathrm{SA} 2$ peptide (construct B); comparison of atomic force fields; further analysis of the nanocarrier build; detailed description of DLS/SLS measurements; further details to the parameters of the atomistic simulations; details to the ssNMR acquisition and processing parameters; movies of the simulated nanocarrier assembly pathway. The Supporting Information is available free of charge on the ACS Publications website at DOI: 10.1021/jacs.5b02919.

\section{AUTHOR INFORMATION}

\section{Corresponding Authors}

*a.m.j.j.bonvin@uu.nl

*e.mastrobattista@uu.nl

*m.h.weingarth@uu.nl

\section{Notes}

The authors declare no competing financial interest.

\section{ACKNOWLEDGMENTS}

We gratefully acknowledge Fouad Soulimani for excellent technical assistance with the FT-IR measurements. MRM was supported by a scholarship from the Iranian Ministry of Health and Medical Education. MW (722.012.002 and 723.014.003), AMJJB (700.56.442) and MB (700.58.102) acknowledge financial support by NWO. MW was supported by a FEBS Distinguished Young Investigator Award.

\section{REFERENCES}

(1) Vauthey, S.; Santoso, S.; Gong, H. Y.; Watson, N.; Zhang, S. G. Proc. Natl. Acad. Sci. U. S. A. 2002, 99, 5355.

(2) Cui, H.; Pashuck, E. T.; Cheetham, A.; Tsai, W.; Mui, S.; Stupp, S. Biopolymers 2009, 92, 298.

(3) Zhao, X. B.; Pan, F.; Xu, H.; Yaseen, M.; Shan, H. H.; Hauser, C. A. E.; Zhang, S. G.; Lu, J. R. Chem. Soc. Rev. 2010, 39, 3480.

(4) Bellomo, E. G.; Wyrsta, M. D.; Pakstis, L.; Pochan, D. J.; Deming, T. J. Nat. Mater. 2004, 3, 244.

(5) Holowka, E. P.; Pochan, D. J.; Deming, T. J. J. Am. Chem. Soc. 2005, 127, 12423.

(6) Xu, X.; Li, Y.; Li, H.; Liu, R.; Sheng, M.; He, B.; Gu, Z. Small 2014, 10, 1133.

(7) Lin, B. F.; Marullo, R. S.; Robb, M. J.; Krogstad, D. V.; Antoni, P.; Hawker, C. J.; Campos, L. M.; Tirrell, M. V. Nano Lett. 2011, 11, 3946.
(8) Gudlur, S.; Sukthankar, P.; Gao, J.; Avila, L. A.; Hiromasa, Y.; Chen, J. H.; Iwamoto, T.; Tomich, J. M. PLoS One 2012, DOI: 10.1371 /journal.pone.0045374.

(9) Torchilin, V. P.; Levchenko, T. S.; Rammohan, R.; Volodina, N.; Papahadjopoulos-Sternberg, B.; D’Souza, G. G. M. Proc. Natl. Acad. Sci. U. S. A. 2003, 100, 1972.

(10) Ellis-Behnke, R. G.; Liang, Y. X.; You, S. W.; Tay, D. K. C.; Zhang, S. G.; So, K. F.; Schneider, G. E. Proc. Natl. Acad. Sci. U. S. A. 2006, 103, 7530 .

(11) Kisiday, J.; Jin, M.; Kurz, B.; Hung, H.; Semino, C.; Zhang, S.; Grodzinsky, A. J. Proc. Natl. Acad. Sci. U. S. A. 2002, 99, 9996.

(12) Frederix, P. W.; Scott, G. G.; Abul-Haija, Y. M.; Kalafatovic, D.; Pappas, C. G.; Javid, N.; Hunt, N. T.; Ulijn, R. V.; Tuttle, T. Nat. Chem. 2015, 7, 30.

(13) Silva, G. A.; Czeisler, C.; Niece, K. L.; Beniash, E.; Harrington, D. A.; Kessler, J. A.; Stupp, S. I. Science 2004, 303, 1352.

(14) van Hell, A. J.; Costa, C. I. C. A.; Flesch, F. M.; Sutter, M.; Jiskoot, W.; Crommelin, D. J. A.; Hennink, W. E.; Mastrobattista, E. Biomacromolecules 2007, 8, 2753.

(15) van Hell, A. J.; Fretz, M. M.; Crommelin, D. J. A.; Hennink, W. E.; Mastrobattista, E. J. Controlled Release 2010, 141, 347.

(16) Yang, S. J.; Zhang, S. G. Supramol. Chem. 2006, 18, 389.

(17) Fatouros, D. G.; Lamprou, D. A.; Urquhart, A. J.; Yannopoulos, S. N.; Vizirianakis, I. S.; Zhang, S. G.; Koutsopoulos, S. ACS Appl. Mater. Interfaces 2014, 6, 8184.

(18) Bielecki, A.; Kolbert, A. C.; Levitt, M. H. Chem. Phys. Lett. 1989, $155,341$.

(19) Weingarth, M.; Bodenhausen, G.; Tekely, P. J. Am. Chem. Soc. 2009, 131, 13937.

(20) Weingarth, M.; Demco, D. E.; Bodenhausen, G.; Tekely, P. Chem. Phys. Lett. 2009, 469, 342.

(21) Baldus, M.; Petkova, A. T.; Herzfeld, J.; Griffin, R. G. Mol. Phys. 1998, 95, 1197.

(22) Cormier, A. R.; Pang, X. D.; Zimmerman, M. I.; Zhou, H. X.; Paravastu, A. K. ACS Nano 2013, 7, 7562.

(23) Takahashi, H.; Viverge, B.; Lee, D.; Rannou, P.; De Paepe, G. Angew. Chem., Int. Ed. 2013, 52, 6979.

(24) Shaw, C. P.; Middleton, D. A.; Volk, M.; Levy, R. ACS Nano 2012, 6, 1416.

(25) Middleton, D. A.; Madine, J.; Castelletto, V.; Hamley, I. W. Angew. Chem., Int. Ed. 2013, 52, 10537.

(26) Leonard, S. R.; Cormier, A. R.; Pang, X. D.; Zimmerman, M. I.; Zhou, H. X.; Paravastu, A. K. Biophys. J. 2013, 105, 222.

(27) Wishart, D. S.; Sykes, B. D.; Richards, F. M. Biochemistry 1992, $31,1647$.

(28) Wang, Y. J.; Jardetzky, O. Protein Sci. 2002, 11, 852.

(29) Hafsa, N. E.; Wishart, D. S. J. Biomol. NMR 2014, 60, 131.

(30) Kabsch, W.; Sander, C. Biopolymers 1983, 22, 2577.

(31) Guo, C.; Luo, Y.; Zhou, R. H.; Wei, G. H. ACS Nano 2012, 6, 3907.

(32) Munoz, A.; Illescas, B. M.; Sanchez-Navarro, M.; Rojo, J.; Martin, N. J. Am. Chem. Soc. 2011, 133, 16758.

(33) Korevaar, P. A.; Newcomb, C. J.; Meijer, E. W.; Stupp, S. I. J. Am. Chem. Soc. 2014, 136, 8540.

(34) de Jong, D. H.; Singh, G.; Bennett, W. F. D.; Arnarez, C.; Wassenaar, T. A.; Schafer, L. V.; Periole, X.; Tieleman, D. P.; Marrink, S. J. J. Chem. Theory Comput. 2013, 9, 687.

(35) Lee, O. S.; Cho, V.; Schatz, G. C. Nano Lett. 2012, 12, 4907.

(36) Antonietti, M.; Forster, S. Adv. Mater. 2003, 15, 1323.

(37) Colherinhas, G.; Fileti, E. J. Phys. Chem. B 2014, 118, 12215.

(38) Cerf, E.; Sarroukh, R.; Tamamizu-Kato, S.; Breydo, L.; Derclaye, S.; Dufrene, Y. F.; Narayanaswami, V.; Goormaghtigh, E.; Ruysschaert, J. M.; Raussens, V. Biochem. J. 2009, 421, 415.

(39) Bakota, E. L.; Sensoy, O.; Ozgur, B.; Sayar, M.; Hartgerink, J. D. Biomacromolecules 2013, 14, 1370.

(40) Lindorff-Larsen, K.; Piana, S.; Palmo, K.; Maragakis, P.; Klepeis, J. L.; Dror, R. O.; Shaw, D. E. Proteins 2010, 78, 1950. 
(41) Schmid, N.; Eichenberger, A. P.; Choutko, A.; Riniker, S.; Winger, M.; Mark, A. E.; van Gunsteren, W. F. Eur. Biophys. J. Biophys. Lett. 2011, 40, 843.

(42) Wang, J. M.; Cieplak, P.; Kollman, P. A. J. Comput. Chem. 2000, 21, 1049.

(43) van Hell, A. J.; Klymchenko, A.; Burgers, P. P.; Moret, E. E.; Jiskoot, W.; Hennink, W. E.; Crommelin, D. J. A.; Mastrobattista, E. J. Phys. Chem. B 2010, 114, 11046.

(44) Wassenaar, T. A.; Pluhackova, K.; Bockmann, R. A.; Marrink, S. J.; Tieleman, D. P. J. Chem. Theory Comput. 2014, 10, 676.

(45) Tieleman, D. P.; van der Spoel, D.; Berendsen, H. J. C. J. Phys. Chem. B 2000, 104, 6380.

(46) Bond, P. J.; Sansom, M. S. P. J. Mol. Biol. 2003, 329, 1035. (47) Sinnige, T.; Daniels, M.; Baldus, M.; Weingarth, M. J. Am. Chem. Soc. 2014, 136, 4452.

(48) van Hell, A. J.; Crommelin, D. J. A.; Hennink, W. E.; Mastrobattista, E. Pharm. Res. 2009, 26, 2186.

(49) Weingarth, M.; van der Cruijsen, E. A. W.; Ostmeyer, J.; Lievestro, S.; Roux, B.; Baldus, M. J. Am. Chem. Soc. 2014, 136, 2000.

(50) Lewandowski, J. R. Acc. Chem. Res. 2013, 46, 2018.

(51) Etzkorn, M.; Martell, S.; Andronesi, O. C.; Seidel, K.; Engelhard, M.; Baldus, M. Angew. Chem., Int. Ed. 2007, 46, 459.

(52) Luca, S.; Filippov, D. V.; van Boom, J. H.; Oschkinat, H.; de Groot, H. J. M.; Baldus, M. J. Biomol. NMR 2001, 20, 325.

(53) Hess, B.; Kutzner, C.; van der Spoel, D.; Lindahl, E. J. Chem. Theory Comput. 2008, 4, 435.

(54) Heinig, M.; Frishman, D. Nucleic Acids Res. 2004, 32, W500. 